\title{
Care workers' experiences discussing financial issues with families facing end-of-life decisions
}

\author{
Paula Hopeck \\ Department of Communication Studies, Bloomsburg University of Pennsylvania
}

\begin{abstract}
Numerous studies have confirmed the presence of financial difficulties for families when a loved one is at the end of life. However, few studies examine the discussions family members have with care workers about financial issues during end of life. The research presented here examines the experiences that care workers have with family members expressing financial concerns and how care workers respond. I conducted in-depth interviews with fifty-eight care workers, defined in this study as clergy, patient advocates, and nurses who had experiences talking with families about financial issues. Transcripts of the interviews served as the data set. I transcribed, coded and analyzed the data. Families talk about financial issues openly, although sometimes guiltily. Some families express difficulties implicitly, and in these cases, care workers often had to piece together information based on other statements and behaviors of the family. Care workers suggest solutions at the interpersonal, organizational, inter-organizational, social, and national levels. Findings also support prior research that it is important for families to have end-of-life discussions before death is imminent so that families may plan accordingly, and offer insights about care workers and their role in making financial discussions easier for families.
\end{abstract}

Correspondence: Paula Hopeck, Department of Communication Studies, Bloomsburg University, 400 E. Second Street, McCormick Center for Human Services 1102, Bloomsburg, PA 17815-1301.

E-mail: phopeck@bloomu.edu

Key words: Finances; end of life, thematic analysis.

Disclaimer: All views expressed in the submitted article are the author's own and not an official position of the institution or founder.

Acknowledgments: Dr. Robert J. Green (Bloomsburg University of Pennsylvania), Dr. Mariaelena Bartesaghi, and the two anonymous reviewers whose comments and feedback strengthened the article.

Conflict of interest: The author has no conflict of interest to declare.

Funding: This work was supported in part by an internal mini-grant from the Office of Research and Sponsored Programs at Stephen F. Austin State University to purchase NVivo 11 software.

Conference presentation: Part of this work was presented at the $100^{\text {th }}$ annual meeting of the National Communication Association in 2014.

Received for publication: 12 May 2020.

Accepted for publication: 5 February 2021.

This work is licensed under a Creative Commons Attribution NonCommercial 4.0 License (CC BY-NC 4.0).

${ }^{\circ}$ Copyright: the Author(s), 2020

Licensee PAGEPress, Italy

Qualitative Research in Medicine \& Healthcare 2020; 4:107-116 doi:10.4081/qrmh.2020.9102

\section{Introduction}

End-of-life financial issues affect families all over the world. ${ }^{1-3}$ In the United States, out-of-pocket and informal care expenses in the last five years of life can cost between $\$ 28,000$ and $\$ 61,000 .{ }^{4}$ Several types of financial burdens exist, including paying for medical bills, paying for caregiving, and taking unpaid leave from work to attend to an ill family member. Of course, these burdens can also occur all at once (see Gardiner, Brereton, Frey, Wilkinson-Meyers, and Gott $^{5}$ for a thorough review). The research presented in this article elaborates on some of these issues from the experience of care workers who are having family discussions. First, this article will explore the existing research on financial issues in healthcare concerning individuals. Next, the article will elaborate on how findings from interviews indicated that care workers and families both find themselves caught in a health care system that forces family members to face difficult options, and leaves individual care workers to help families find solutions.

Several studies have already examined how families are affected by financial issues based on the diagnosis. Zafar and colleagues ${ }^{6}$ studied financial issues of those undergoing cancer treatments and their families. They named the financial hardships that accompany cancer treatment as financial toxicity, defined as "the negative personal financial impact of cancer care among the underinsured" (p. 388). After a stroke, Medicare will cover invasive procedures at the hospital, but not the personal care needed afterward, including assistance with bathing and dressing. ${ }^{7}$ Financial toxicity and the reality of medical 
expenses are often unexpected, leaving those receiving treatment and their family members ill-prepared in a situation that is already emotionally draining.

Financial issues should not be ignored when weighing end-of-life options. Covinsky and colleagues ${ }^{8}$ argued that finances do - and should - play a role in end-of-life decisions. One-fourth of participants in their study indicated that illness had caused financial hardship, including losing most or all their savings, or drastically altering plans (e.g., downsizing a home or delaying education). Tucker-Seeley, Abel, Uno, and Prigerson ${ }^{9}$ noted families cope with two difficulties: the emotional loss of the family member and the depletion of financial resources. In some cases, the two are intertwined, such as when the family member who was ill served as the primary source of income for the family.

Financial issues may affect the care that individuals request. One study found that patients who have used up their financial resources have more costly, aggressive treatment because out-of-pocket expenses will be lower than what is covered by Medicare. ${ }^{9}$ Conversely, other researchers have found that financial difficulties lead to less costly, more palliative treatment..$^{6-8}$ For example, one-fifth of participants in one study ${ }^{6}$ took less than their prescribed medicine, or skipped appointments to help pay for their treatment, and a smaller percentage refused treatments due to cost. In another study, financial difficulty was found to be associated with choosing comfort measures over aggressive treatments. ${ }^{8}$ These examples indicate that costs have some influence over the decisions that are made. Thus, knowing the financial status of the person undergoing treatment and the family is critical to creating the plan of care.

Those receiving treatments tend to be more concerned about end-of-life finances than their proxies, ${ }^{10}$ or those they have selected to make their decisions. They want to discuss costs with physicians before making major decisions. ${ }^{11}$ Scholars encourage physicians to be aware of financial burdens and direct them to available resources, such as social workers, ${ }^{8,12,13}$ or include treatment costs in advanced care planning. ${ }^{14,15} \mathrm{Few}$ physicians report knowing the financial difficulties of their patients. ${ }^{11}$ Oncologists in one report recognized the importance of discussing costs, but may not be able to hold effective discussions concerning costs. ${ }^{6}$

The uninsured and those on Medicaid can be mistreated by medical personnel. ${ }^{16}$ Based on interactions with physicians, those on Medicaid or without insurance can feel ashamed. These individuals may not go to the doctor as often as one way of dealing with the shame. ${ }^{16}$ Notably, several of the studies cite the Affordable Care Act's expansion of Medicaid as influential because Medicaid recipients have long been perceived as lazy or undeserving of such benefits. ${ }^{16}$ Additionally, studies report that once Medicaid was expanded, Medicaid recipients experienced poor treatment from medical staff (from doctors to receptionists) based on their insurance status. ${ }^{16,17}$
These studies cast light onto the tenuous state and structure of medicine when it comes to financial issues. Although, on the one hand, medical personnel recognize that talking about finances are important to the healthcare plan, the person undergoing treatment may not want to because of prior treatment by medical staff, feeling that they are stigmatized in some way. ${ }^{18,19}$ Another gap is that the studies do not mention how finances might impact end-of-life care, other than Medicaid patients are also low-income. This would not cover individuals who are not on Medicaid but insurance may not cover enough of what they need for care. One of the few studies that did address financial issues and end of life specifically was conducted by Bossuyt et al., ${ }^{2}$ who surveyed general practice physicians on end-of-life preferences and educational level of families. They found that lower education levels were correlated with accessing fewer end-of-life treatment options and seeking fewer resources. ${ }^{2}$ However, the study was conducted in Belgium, where there are policies for equity in palliative care options, and the study did not explore socioeconomic situations of those undergoing treatment.

From the existing literature, it is clear that there are several issues in the healthcare delivery system in terms of finances. What is still unclear is how finances impact end-of-life discussions. Additionally, the experiences of individuals who have experienced talking about finances have been documented, but less about the experiences of the care workers who are helping the individuals. Therefore, a research question is posed: what types of end-oflife financial concerns are expressed to care workers, if any? Additionally, once care workers are aware of financial issues, the question becomes what happens next. So, a second research question is posed: how do care workers alleviate the financial concerns of family members?

\section{Materials and Method}

The findings reported in this manuscript are part of a larger dataset from a previous study. The intent of the larger study was to examine experiences of care workers who managed end-of-life discussions with family members. All recruitment and interview protocol materials were approved by the Institutional Research Board prior to data collection.

\section{Participants}

In the initial stages of planning the overall study, several individuals of the medical team care for the person receiving treatment. I wanted the richest data set and to explore several parties that may deal with end-of-life discussions, so chose to utilize maximum variation sampling, which allows the researcher to determine if there are similarities between those who have different backgrounds and experiences. ${ }^{20}$ Patient advocates act on behalf of oth- 
ers, serve as their spokespersons, and help with any issues facing those under treatment or their families. ${ }^{21-23}$ Clergy, in addition to their primary role as spiritual and religious support, provide emotional support, ${ }^{24,25}$ and establish trust with those under treatment and families more so than anyone on the medical staff. ${ }^{26}$ Finally, nurses are typically assigned fewer patients than physicians, and thus develop rapport. ${ }^{27,28}$ Based on this research, I decided to exclude physicians from the study. Additionally, social workers sometimes serve in a patient advocacy capacity (as I learned in my initial recruitment), and they were also included among the participants.

\section{Recruitment}

I recruited participants through personal contact and listservs. I contacted independent consulting patient advocates, patient advocates (or representatives) of local hospitals and leaders of local churches. I also requested access to organizational listservs for national groups of patient advocates, nurses, and clergy. Finally, I attended nursing conferences and approached presenters individually to ask if they would like to be interviewed. Some participants contacted me because they heard about the study from mutual acquaintances or from other participants. Recruitment attempts yielded 71 completed interviews, although only 58 participants discussed financial issues. These 58 participants included 14 hospital chaplains and parish clergy, 18 patient advocates, patient representatives, or social workers, and 26 nurses, hereafter referred to collectively as care workers. These care workers represented several different types of organizations, and their specific organizations will be identified below.

\section{Data collection}

I conducted in-depth, semi-structured interviews with participants, 44 over the phone and 14 in person throughout 2012. Interviews lasted between 18 and 118 minutes, averaging 53 minutes each. I asked all participants if they participated in or observed family discussions with patients occurring at the end of life, then followed up with appropriate probing questions based on their responses. Later in the interview, I asked if families ever mentioned or expressed concern about finances. Occasionally, participants told me how financial concerns arose during memorable family discussions. Those situations were also included in the analysis.

\section{Analysis}

I recorded, transcribed, and coded each of the interviews. During transcription, all identifying information was removed and each participant assigned a pseudonym.

Spradley ${ }^{29,30}$ provided the guidance for analyzing interview data. I started with open coding, where I conducted line-by-line coding following transcription. Any response that had to do with finances was categorized in NVivo 11 as finances. Similar to the constant comparative method, when certain patterns from the initial interviews became noticeable, I began to ask other structural questions,$^{29}$ meaning that I incorporated findings from earlier interviews into future interviews. For example, I reframed the financial issue as, do participants ever say, "I want to do what's best but I don't..." based on terminology used in prior interviews. After the data was coded, I specifically focused on the finances code, known in NVivo as nodes. The first step that I took was to divide the responses between those who stated affirmatively that they held discussions about finances, or that finances had somehow played a role in their experience, and those who stated that finances were never mentioned.

From there, to help organize the data further, I conducted a domain analysis. A domain analysis simply allows the researcher to develop semantic relationships between terms. ${ }^{29} \mathrm{~A}$ term that a participant used, toughies, was an in vivo (or in the voice of) code. ${ }^{31}$ To analyze what is a toughie and what is included, I looked to the rest of her statement to understand to what she was referring, specifically she introduced the term as a situation where "they [the family members] wanna keep them [the patient] alive until the end of the month so that they'll die the first of the next month so they don't lose the social security benefits for the month." Based on this description, a toughie did not fit into the overall financial concerns of caregiving, medical, or funeral related to end of life costs. Participants who did mention this type of situation noted that this was an overall financial issue, not one related specifically to a type of expense. Similar situations were noticed in eight other cases given by participants. This will be discussed below in the componential analysis. Toughie was used by one participant and I would not classify it as a universal folk term (or a term used by several participants in their voice $)^{30}$ by care workers, but similar situations were described. Another participant described the rationale behind making the decision based on finances as not so nice. The phrase toughie captured this succinctly, and the emotional toll of the situation to all involved.

Following a domain analysis, Spradley recommends a taxonomic analysis. ${ }^{29,30}$ As the frequency of financial discussions became apparent, in later interviews, I began to ask participants for examples of financial issues. When doing this, I examined each of the domains related to finances and listed more specifics. For example, paying for long-term care is an example of a caregiving expense. Funeral costs include burial, cremation, and religious services. The full taxonomy is in Appendix A.

Once I listed all the taxonomies, I conducted a componential analysis. Componential analysis allows you to identify various attributes of a folk term. ${ }^{29,30}$ So, to use the example of a toughie, since this was an example used by a participant, toughie is a situation encountered by care 
workers when a family's decisions are affected by financial status. A toughie usually was an issue where the family was reliant on the person who is receiving treatment's welfare or social security check and delayed withdrawing treatment. A toughie could also be a case where families brought personal financial issues into the hospital, such as a transfer of property ownership, but this was to a lesser extent. Toughies were also situations that were expressed differently. This was also included in the overall analysis, namely, how these financial concerns were expressed.

From there, I conducted a thematic analysis. For Spradley, themes connect subsystems together. Spradley defined a theme as any cognitive principle, tacit or explicit, recurrent in a number of domains and serving as a relationship among subsystems of cultural meaning (p. 186). ${ }^{29}$ For Spradley, themes can apply to multiple situations, or domains, when speaking about analysis. One of the themes that kept arising was the unstated but perceived expressions of financial issues. These were not necessarily openly stated, but perceived as related to financial issues by caregivers. These also presume that while financial issues exist, there are other mechanisms that families deal with the exist beyond revealing them to care workers.

In the results section below, the domains and taxonomies of the financial issues will be explored in greater depth.

\section{Results}

The first research question asked, what financial concerns, if any, are expressed to care workers? As noted above, under the domain of end of life financial concerns were caregiving $(n=25)$, insurance $(n=16)$, funeral $(n=$ $5)$, and medical $(n=3)$ expenses. Beginning with the strict inclusions of the domain analysis, ${ }^{29}$ such as caregiving, insurance, medical costs, and funeral costs are kinds of financial expenses related to end of life. Losing a job is a result of caregiving (cause-effect), ${ }^{29}$ and hospital or government will pay medical bills are beliefs about healthcare (rationale)..$^{29}$ One tacit, overall theme that kept recurring was the strain of a bureaucratic health care system that is a burden for those who are not usually considered financially unstable, and utterly unsympathetic to those who are financially unstable. This theme not only affects those utilizing the healthcare system, but also affects those in the health care system, making care workers in some cases piecing together and searching for options to help, and at worst, forcing themselves to detach.

Several care workers explained that financial concerns are not uncommon to end-of-life discussions $(n=47)$. About half of the concerns related to the general stress of determining the caregiving plan $(\mathrm{n}=25)$. The examples presented below sample some of the complexities that are associated with end-of-life financial issues.

Scott, ${ }^{1}$ a hospital chaplain, explained the common situation of families:
"It happens every day because they go, for instance, the patient's terminal, they wanna go home to die, family members, everybody works, who's gonna take care of that patient? You know, "Can we afford to hire a home health? Probably not. Now what do we do with 'em?" So there's always that dilemma- not always, many times that dilemma, that's where the finance comes in even more so, and it's getting worse rather than better... it's becoming more and more of an issue and of a dilemma, "Who's gonna take of 'em when we kick 'em out of the hospital? I wanna do the right thing for 'em, but I can't lose my job for them to live 6 months at home and I can't get my job back ... we've got kids in college and I need to support them, their tuition, I can't afford to take Mom into the house now and lose my job and lose my way of supporting my family."

Scott's example highlights the complexity of end-oflife caregiving that includes several issues that care workers mentioned over the course of interviews. Namely, having the family members become caregivers may not be a possibility because the family must work. If a family member chooses to stay home, they can take leave as part of the Family Medical Leave Act (FMLA) which Nicole, an oncology nurse navigator, explained as "they have to be able to hold your job legally, they just don't have to pay you."

Olivia, a hospital patient representative, explained:

"The financial aspect is a huge thing for people, it just- it is, especially for the elderly patients, you know, they're living so much longer and they're in their 80 s and money's running out and how do you take care of them and it does come down to the family having to pitch in and take care of them, and yeah, the financial aspect of it is really difficult because you know these people are having copays and deductibles and all of that as well."

Olivia's example emphasizes the burden placed on families, and money's running out indicates that several families are unprepared for the financial burdens at end of life.

Similarly, Richard, a hospice nurse, noted the frequency of financial issues and lack of

knowledge about financial resources.

"It seems like it's weekly that I come up with those sort of things, I mean I had another case where a lady, just ran out of money on RCFE [residential care facility for the elderly] so what are we gonna do? Ended up having to find a skilled facility that

\footnotetext{
${ }^{1}$ All participant names are pseudonyms.
} 
would take her. So there, you have to pay your monthly, there's no government [help]. I hear that Medicaid is now starting to look at helping with that but for the most part, they don't do anything."

In addition to the frequency of events, Richard's example reinforces that ultimately, it is the responsibility of the family to determine the course of action and to pay the bill.

These three examples provide context for the range and frequency of financial problems that families may encounter in terms of caring for a family member at the end of life.

Another issue that was raised was hospice. Hospice overall was lauded by the participants, but Shelby, a palliative care nurse, explained that challenges can arise when requesting hospice. Referring to a situation where a woman was brought into the hospital and her son decided she should receive hospice, Shelby recalled:

"There was no question that hospice would have been paid for and the family wouldn't have had any expense and we got hospice arranged, he [the son] talked to two different hospices and the nursing home called us three times and said, "Are you sure?" and even the son called me and I prepared him, I said, "The nursing home is gonna call you and tell you, they're gonna try and do therapy with her." He goes, "Why would they do therapy?" I said, "I don't know, but they're going to tell you that. All you have to do is say, 'No, I want hospice, we want comfort measures only, we want her to be comfortable." They called him, they called our social worker twice and said, "Are you sure he understands?" And we're like, "This woman's 99 years old, can barely talk, can't walk but somehow they're trying to what we call "skill her," they want that extra money from Medicare because they get more money from Medicare if they're not with hospice so she's a perfect example of what they're doing is wrong because anybody, anybody with no healthcare experience at all could have said, "You can't do therapy on this woman, she's actively dying" but they called three times to try and get her skilled and not let her have hospice so those are things ... that I am having a hard time with."

Without a care worker explaining and supporting, it is plausible that others might reverse their decision and not choose hospice.

Other care workers talked about how hospice, while beneficial, is not sufficient for some families or the requirements still place a strain on them. Teri, a nurse who had worked in both hospice and oncology, recalled, that people are surprised "that hospice isn't somebody coming and living at your house that's paid for by Medicare, even though it's paid for by Medicare, we weren't in the home 24 hours a day, that was very shocking to people." Kathryn, a nurse liaison for a hospital system, explained, "even with hospice, you only get a couple hours a day, so somebody really has to be there, and often it is not even so much that the patient financial end of it, it is that they have to take off of work, and what impact it has on their income in addition to whatever happens with the family." Although hospice is beneficial, there are still some stipulations that can place a strain on families.

Financial concerns towards end of life also include funeral issues. Three clergy members included the discussion of opting for cremation instead of burial based on finances. Rachel, a nurse-turned-hospice chaplain, noted that some families she works with "are almost kind of forced to go with like a place that does affordable cremations and things like that even if that wouldn't be their first choice because that's really all they can do." Rachel's description of being forced and cremation not being their first choice indicates that, while there are some options about decisions to make, the decisions themselves may be made for the families based on their financial status.

One rabbi, Kara, explained that financial issues put some in contention with what their own beliefs. After explaining Jewish burial customs, Kara noted that now "People know it does cost more to have a full burial with opening a grave and everything like that, than if you do cremation, it's less expensive." Because cremation conflicts with religious beliefs and law, it also demonstrates the strain placed on families. Kara explained there is a section in our cemetery that indicates that those who are unable to afford the traditional burial may be forced to be in a section of the cemetery that identifies them as not having the financial resources.

Although financial issues are common, some care workers observed that families feel guilty about expressing concerns. Lily, a clinical social worker for an Intensive Care Unit (ICU), observed financial difficulty is a "very, very common concern ... people always say, 'I feel so bad telling you this but ..." "Similarly, when asked if families ever talked about financial issues, Naomi, a nurse practitioner who also served a director of a palliative care center for a community hospital, said, "they do, and they talk about it guiltily, 'I'd love to be able to take care of my mother, but I have to work, and I can't afford to take care of my mother, and I have to choose one of them, '... and that's a very difficult choice." Hannah, a nurse for a large health organization, also said that families can feel like "failures" in these situations.

In addition to openly expressing financial issues, families may also express concerns implicitly. Fifteen care workers observed that certain behaviors and comments indicated there were problems. One domain therefore became a means-end relationship, ${ }^{29}$ such as stating I have to work, saying We need food, and complaining about care are ways to express financial issues. For example, family 
members might say an expensive treatment was not an option, or respond to their loved one needing more inhome care with have to work. Samuel, a Unitarian minister, stated, "[Family members] 'll say, 'Oh gee, we need food,' but they won't say, 'Dad's dying is breaking us.' Because I don't think people give themselves permission to say that and ... you don't want cost to be the reason you make a medical decision." Samuel's comment reflects that other areas of family life suffer from financial issues, including not having enough food. However, families may be unwilling to admit the financial burden of the illness. Similar to the families who discuss financial issues guiltily, people do not want to discuss how costs are disrupting their lives.

The toughies. As described above, there were nine care workers who referred to some situations as toughies, not-so-nice reasons, and heart-sinking situations for making decisions. Eleven participants in total mentioned that some families relied on the person undergoing treatment as a significant source of income, which was aptly named by Yvonne, a patient advocate consultant who also served on hospital ethics committees, who said "[some families] wanna keep them alive until the end of the month so that they'll die the first of the next month so they don't lose the social security benefits for the month. Those are toughies."

Roma, a nurse and unit-based educator, explained that family members never outright discussed financial problems with her, but did say:

"I have heard them say quite the opposite, you realize after digging around a little bit, they're keeping their 91-year-old mother alive, really sick and really needs to move on and something comes up and all of a sudden, you realize what's going on ... they won't say, "Well, we need her income" but it's just like little things like, "We don't know how we're gonna cope without her, we live with her," but that is when the light bulb goes on in your head ... "Okay, now it's becoming clear."

Sandra, a bedside hospital nurse, said that no one ever spoke with her directly about financial difficulties. However, she recalled one situation where a man disappeared from the hospital after his wife died. The staff later learned that he had disappeared because "he had no money-to bury her."

Based on these comments, care workers can sometimes determine the extent to which families may be concerned about finances without directly addressing them, and be aware of potential cues for financial concerns. This is not to say that every statement of I have to work from a family member is an indirect expression of financial problems, but perhaps should be explored in more depth by care workers.

A smaller number of care workers also explained that families had no idea what was included in their healthcare concerns. Sandra also noted with the families she works with, "I think actually if they felt they had to pay for it then they would have been more prone to pull the plug ... they really believe that the government is going to pay for it." Ophelia, a private practice patient advocate, also noted that in her initial assessment of her clients, she goes through financial issues: "because first of all, a lot of people don't understand how their insurance even works."

It should be noted that situations where families appeared to hide issues or had an awareness of issues generally garnered sympathy from participants. Some participants had a certain detachment or even numbness when talking about those issues, such as Sandra from above, and Kathryn, who noticed similar circumstances for some families.

"You get these patients that the families will not write the DNR/DNI because financially they're living on the checks so they try to prolong it, and it's interesting because very often those patients don't have visitors, or very, very infrequent visitors, but it's that income that they're worried about."

Other participants had a more critical view. Speaking about one family he had worked with, Scott said, "there was no question the family was wanting them to live as long as possible because of the welfare check." Nathan, a private practice patient advocate, did not believe it was in his position to talk about financial issues with families, stating, "I consider that to be their problem."

Helen, an ICU nurse, recalled a situation:

"We had one patient...we could not get him any better than what he was and he was just going down the toilet, and the wife, she agreed to withdraw life support. But she couldn't afford the funeral. Didn't wanna withdraw life support for two reasons. Number one, she had to wait four days for his disability check to come ... and then she couldn't afford a funeral ... so we held that patient before we withdrew life support for like four days. Until she got her friggin' check ... and then she withdrew life support and he died like within an hour, that's how severe he was."

These types of situations may in fact be causing a perpetual cycle of dysfunction in the medical field well outside the scope of care workers, families, and individuals receiving treatment. Based on this research, even individuals in stabile financial situations find themselves at the mercy of an unsympathetic system that forces them to choose between losing their job to become full-time caregivers, taking unpaid leave under FMLA, or paying exorbitant out-of-pocket expenses for caregiving that may not be covered entirely by their loved one's insur- 
ance. Of course, there are individuals whose situation is even worse.

\section{Solutions to financial concerns in end-of-life discussions}

Granted, not all care workers were unsympathetic, and many did try to help. Research question two asked how care workers try to help. Looking at each of the identified financial situations, I separately coded situations where the care worker provided a solution or help. These were coded openly, and then axially, ${ }^{31}$ where I looked for common relationships between individual solutions. I recognized there were five general categories that solutions tended to fall under. The first was interpersonal, where care workers worked one-on-one with families to help them with finances, including discussing finances or personally writing letters to employers asking for time off. The second was organizational, where care workers asked other members or departments of their own organization for help. This included parish pastors reaching out to their congregants. The third, inter-organizational, included strategies where care workers reached out to organizations outside of their own, such as volunteer agencies or funeral homes. The fourth strategy, social, included care workers asking family members to ask their social networks for help. The final strategy, national, included when care workers would remind family members of national resources for them, such as FMLA or Veteran's Benefits.

Several of these strategies were straightforward, and involved connecting family members to resources that would be helpful. Specifically, this section will focus on the interpersonal strategies, or how care workers connect with families one-on-one. These strategies typically involved care workers personally signing papers and writing letters to employers related to FMLA. Some care workers mentioned they would help them with the paperwork. For example, care workers can sign the paperwork or write personal letters to excuse the family member from work.

To a lesser extent, care workers tailored their message to the families. Gayle, a clinical social worker for an ICU, related how she deals with the statement, "I don't know if I can take care of Mom," another nuanced expression of potential financial difficulty, and how she thinks, "my role in that is really just helping them think through, 'Okay, well, what are your options and how can I help you through that." "Gayle specifically mentioned that instead of recommending to the family member that they should look into certain services, that she offers to look into those services herself. Importantly, Gayle noted she offers help on a case-by-case basis, meaning that this might not be covered in all situations where it is needed. It should also be noted that several of the patient advocates that participated often handled cases of individuals who, in addition to caregiving expenses, could also afford to hire a patient advocate consultant.
While care workers noted hearing about financial concerns frequently, only two indicated that part of their solution was to validate the concerns of family. Lily told family members, "Of course, of course you would be [worried about finances], that's normal." Lily [points] families in the right direction about where to find help. Hannah, a nurse, reassured family members who feel like failures:

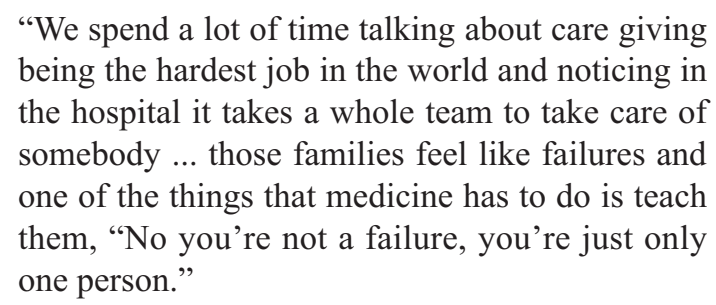

Although these are small statements, they may also alleviate one more concern during a difficult time for family members. These statements may also help normalize financial discussions and encourage family members to accept help offered to them. Hannah's statement also includes the responsibility of medicine in alleviating concerns, one of only a few that appeared to recognize the healthcare system itself is flawed and does not work for a majority of people.

\section{Discussion}

The research presented in this article focused on the financial concerns that families express to care workers, and how care workers help Families do express financial concerns toward the end of a family member's life, including how to handle multiple financial responsibilities. However, some of these concerns are expressed indirectly. I am not claiming that financial reasons or costs of care were the sole reason for making decisions. Most care workers, when asked about financial influences, did explicitly state no one made decisions based on finances alone. There is limited available research that examines the financial concerns expressed to care workers and how care workers respond. The research presented here is one of the few to do so.

It should be noted, that this research was conducted in 2012, immediately following the Great Recession, and soon after the implementation of the Affordable Care Act (ACA). However, the research asked participants to draw on any experiences that they had over the career, and few situations were given a timeframe. It can be assumed that time is not necessarily a factor, and that financial issues have affected several people over the years. While participants occasionally mentioned factors related to ACA (e.g., visiting hours expanded to 24 hours a day, and questions about the non-existent death panels), none of the situations noted above were a result of ACA. Additionally, at the time of this writing, there is discussion of the ACA 
going before the Supreme Court, putting coverage for thousands of Americans at risk. These situations should be discussed to highlight some of the discussions that need to happen if people are unable to financially support themselves during end-of-life moments. This may also lead to a greater burden on care workers to help families find a solution to their end-of-life financial issues, or create further detachment.

Many participants noted in their solutions that financial planners and counselors were available through the hospital. However, a discussion may only occur when families vocalized concerns; whereas the more implicit expressions should also be assessed. In addition to the resources that hospitals offer, one area to consider would be greater transparency in what is included in health care plans, such as long-term care insurance, and in-home care. Patient advocates discussed families' understanding about what health insurance covers and what is financially reasonable. Other research has already established that those undergoing treatment would like to have discussions about the costs of care. ${ }^{11}$ If such discussions were held at an early stage of the illness, the families might also be better prepared for what decisions to make, and have greater knowledge of what support is available. Granted, if the illness is recent, families may be unable to process what is being said or see the long-term implications of decisions. However, this only provides further support for having end-of-life discussions well before decisions have to be made. ${ }^{32}$ Finally, hospice is an inexpensive alternative for end of life, and often has several benefits in terms of quality of life. Hospice, while invaluable, is widely misunderstood and also rife with problems, as explained by one of the participants. But, even if hospice is requested by family members, they may face pushback if the individual is in a nursing home and on Medicare, who pays differently if the individual is on hospice, as opposed to skilled. This complex relationship between Medicare, hospice, and nursing homes has been documented before, ${ }^{33}$ and a more directed discussion about this relationship should be explored for the future.

The most important areas of focus concern how care workers can talk about financial issues effectively with families without being judgmental. Authors of one study concerning religion and end of life encouraged care workers to explore meaning behind religious and spiritual statements that family members made without making judgements about religion. ${ }^{34}$ Similar principles can be applied to talking about financial resources. For example, following up on why a treatment plan is not an option or why they feel they will be unable to cope without her. Knowing something is not an option would be part of the care plan, so it is critical to understand why family members and/or those undergoing treatment are making such statements. Understanding the reasons why family members have these concerns may help care workers refer family members to the resources they need. These need not be financial resources, but also social support.

As noted by Hannah, one of the nurses in this study, medicine should consider it part of their plan of care to help families to see that caregiving is a difficult job and they should not feel like failures when they ask for help. But perhaps even more so what is needed is that care workers need better training for helping individuals who are facing financial hardships, including anti-bias training. The bias may be a result of being part of a culture of a system that sees financial issues as an individual problem, and is utterly unsympathetic to the lack of resources available for working families, and to the potential needs of ailing members who want to be at home and cared for by their families.

That is not to say that care workers do not already have resources and do not help, but looking at the types of solutions care workers offer, patient advocates have the widest range of solutions for families. Perhaps including patient advocates automatically in any discussion of illness would be a resource to help families. Clergy members did not hear as many financial concerns, which may be related to their role as a spiritual counselor. Family members may have felt uncomfortable revealing financial hardships to them, perceive it was inappropriate to do so, or feel as though they might be stigmatized by the church in the future. However, Koenig ${ }^{35}$ recommended more collaboration between religious communities and healthcare workers, since religious communities can provide networks for outpatient care and volunteering. Similar services could also be applied to financial issues. Indeed, some of the participants in this study talked about how they would reach out to the members of the church (or synagogue or mosque) and ask for help.

Additionally, although several care workers discussed financial issues, only two talked about how they validated the concerns of the family. If care workers do not normalize financial issues, families may be less likely to voice concerns. This could even include being overly sympathetic or pitying family members, which might not be as productive. Finally, situations like the toughies exist with little direction about how to help or what to do. It should also be noted that some of the care workers openly expressed frustration with family members who would be considered the toughies, which, if perceived by the family, is not productive either. Another area for care workers would not just be what to say to family members, but training them to say it as neutrally as possible.

One area that might add an interesting dimension of this type of work would be the experiences of physicians and hospital administrators. Although I made the decision to exclude physicians based on prior research ${ }^{21-28}$ about who builds rapport with families, the insight of physicians would also be of interest to the growing body of literature on the topic. General practice physicians, who build relationships with their patients over time, may have more ex- 
perience with dealing with the topic. Those who have financial difficulties may have also built a rapport with the physician over the course of treatment and therefore feel more comfortable disclosing their needs to them.

Conversely, families may be more hesitant to express financial difficulties to physicians, Several researchers have already established that Medicaid recipients feel stigmatized by physicians and other providers because their insurance (or lack thereof) status. ${ }^{17-19}$ Hospital administrators may not have direct contact with family members during discussions, but they may have more contact with families concerning billing and finances. Olivia, a patient representative, also explained in her interview that, following treatment, those who had been treated would contact her to complain about care, stating that:

"Patients have actually said this to me, 'If I go to my mechanic and my car's not fixed, I don't pay him,' people say that kind of thing...I see more complaints related to billing even though patients don't say that, they say it's about their care and treatment, it's the financial that's really driving them to complain or they probably would have complained that day or a week later, not six months later when they get the bill."

Because this article concerned family expressions, this statement did not fit into the overall themes and it could not be determined that this would apply to families. There are two implications of her statement. First, it is an interesting statement about how individuals can take control of their care and navigate a difficult system. Future research should examine perceptions if complaints are about care, or about finances. Second, it would be interesting to see if families also apply this strategy after their loved one has passed away. Longitudinal research examining family satisfaction with care over time that correlates with financial difficulties may also yield interesting results.

\section{Conclusions}

The research here indicates that it is not just a lack of insurance that can lead to issues, but a lack of overall financial resources to pay for in-home care, funeral expenses, and medical expenses. The question of end of life and family finances has no easy answers. However, greater understanding of the issues that families face can help hospitals facilitate discussions and create pathways towards alleviating end-of-life issues. Research can also help care workers navigate the system that they find themselves guiding families through. This study offers insight of the issues that families face, including understanding the underlying concerns that may exist. Knowing the concerns can allow us to explore creative solutions aimed at helping families during end of life.

\section{References}

1. Aoun SM, Kristjanson LJ, Currow DC, Hudson PL. Caregiving for the terminally ill: At what cost? Palliative Med 2005; 19:551-5.

2. Bossuyt N, Van den Block L, Cohen J, et al. Is individual educational level related to end-of-life care use? Results from a nationwide retrospective cohort study in Belgium. J Palliat Med 2011;14:1135-41.

3. Gott M, Allen R, Moeke-Maxwell T, et al. 'No matter what the cost:' A qualitative study of the financial costs faced by family and whanau caregivers within a palliative care context. Palliative Med 2015;29:518-28.

4. Kelley AS, McGarry K, Gorges R, Skinner JS. The burden of health care costs in the last 5 years of life. Ann Intern Med 2015;168:729-36.

5. Gardiner C, Brereton L, Frey R, et al. Exploring the financial impact of caring for family members receiving palliative and end-of-life care: A systematic review of the literature. Palliative Med 2014;28:375-90.

6. Zafar SY, Peppercorn JM, Schrag D, et al. The financial toxicity of cancer treatment: A pilot study assessing out-ofpocket expenses and the insured cancer patient's experience. Oncologist 2013:18;381-90.

7. Tilden VP, Thompson S. Policy issues in end-of-life care. J Prof Nurs 2009;25:363-8.

8. Covinsky KE, Landefeld CS, Teno J, et al. Is economic hardship on the families of the seriously ill associated with patient and surrogate care preferences? Arch Intern Med 1996;156:1737-41.

9. Tucker-Seeley RD, Abel GA, Un $\sim$ H, Prigerson H. Financial hardship and the intensity of medical care received near death. Psycho-Oncol 2015;24:572-8.

10. Hawkins NA, Ditto PH, Danks JH, Smucker WD. Micromanaging death: Process preferences, values, and goals in end-of-life medical decision making. Gerontologist 2005;25:107-17.

11. Alexander GC, Casalino LP, Meltzer DO. Patient-physician communication aboutout-of- pocket costs. J Am Med Assoc 2003;290:953-8.

12. Lathan CS, Cronin A, Tucker-Seeley R, et al. Association of financial strain with symptom burden and quality of life for patients with lung or colorectal cancer. J Clin Oncol 2016;34:1732-40.

13. Masel EK, Berghoff AS, Schur S, et al. The PERS20N score for systemic assessment of symptomatology in palliative care: A pilot study. Eur J Cancer Care 2016;25:544-50.

14. Donley G, Danis M. Making the case for talking to.patients about the costs of end-of-life care. J Law Med Ethics 2011;39:183-93.

15. Widera E, Steenpass V, Marson D, Sudorc: R. Finances in the older patient with cognitive impairment: He didn't want me to take over. J Am Med Assoc 2011;305:698-706.

16. Martinez-Hume AC, Baker AM, Bell HS, et al. "They treat you a different way:" Public insurance, stigma, and the challenge to quality health care. Cult Med Psychiatry 2017;41:161-80.

17. Allen H, Wright BJ, Harding, Broffinan, L. The role of stigma in access to health care for the poor. Milbank Q 2014;92:289-318.

18. Hirsch JK, Sirois FM, Visser PL, et al. Perceived stigma and health-related quality of life in the working uninsured: Does 
thwarted belongingness play a role? Stigma Health 2019;4:1-10.

19. Whittle HJ, Palar K, Ranadive NA, et al. "The land of the sick an 4 the land of the healthy": Disability, bureaucracy, and stigma among people living with poverty and chronic illness in the United States. Soc Sci Med 2017;190:181-9.

20. Patton M. Qualitative evaluation and research methods. Beverly Hills, CA: Sage Publications; 1990.

21. Baldwin MA. Patient advocacy: A concept analysis. Nurs Stand 2003;17:33-9.

22. Petronio S, Sargent J, Andea, L, et al. Family and friends as healthcare advocates: Dilemmas of confidentiality and privacy. J Soc Pers Relat 2004;21:33-52.

23. Schwartz L. Is there an advocate in the house? The role of health care professionals inpatient advocacy. J Med Ethics 2002;28:37-40

24. Ford T, Tartaglia A. The development, status, and future of healthcare chaplaincy. South Med J 2006;99:675-9.

25. Wittenberg-Lyles E, Parker Oliver D, Demiris G, et al. Communication dynamics in hospice teams: Understanding the role of the chaplain in interdisciplinary team collaboration. J Palliat Med 2008;11:1330-5.

26. Johnson KS, Elbert-Avila KI, Tulsky JA. The influence of spiritual beliefs and practices on the treatment preferences of African Americans: A review of the literature. J Am Geriatr Soc 2005;53:711-9.

27. Bailey JJ, Sabbagh M, Loiselle CG, et al. Supporting families in the ICU: A descriptive correlational study of informational. support, anxiety, and satisfaction with care. Intens Crit Care Nur 2010;26:114-22.

28. Hebert K, Moore H, Rooney J. The nurse advocate in endof-life care. Ochsner J 2011;11:325-9.

29. Spradley JP. The Ethnographic Interview. Long Grove, IL: Waveland Press; 1979.

30. Spradley JP. Participant Observation. Long Grove, IL: Waveland Press; 1980.

31. Tracy SJ. Qualitative research methods: Collecting evidence, crafting analysis, communicating impact. Malden, MA: Wiley-Blackwell; 2013.

32. Li H, Stewart BJ, Imle MA, et al. Families and hospitalized elders: A typology of family care actions. Res Nurs Health 2000;23:3-16.

33. Miller SC, Mor VNT. The role of hospice care in the nursing home setting. J Palliat Med 2002;5:271-7.

34. Lo B, Ruston D, Kates LW, et al. Discussing religious and spiritual issues at the end of life: A practical guide for physicians. J Am Med Assoc 2002;287:749-54.

35. Koenig HG. Spirituality in patient care: Why, how, when, and what 2 nd ed. West Conshohocken, PA: Templeton Press; 2007. 